\title{
A Study on Pressure Loss by the Material of AHU-linked Vegetation Bio-filter and its Operational Energy Efficiency
}

\author{
Tae-Han Kim * So-Dam Lee ${ }^{2}$, and Sung-Eun Park ${ }^{3}$ \\ ${ }^{1}$ Department of Environmental Landscape Architecture, Sangmyung University, Cheonan 31066, South Korea \\ ${ }^{2}$ Department of Environmental Landscape Architecture, Graduate school, Sangmyung University, Cheonan 31066, South Korea \\ ${ }^{3}$ College of General Studies, Sangmyung University, Seoul 03016, South Korea
}

\begin{abstract}
Recently, the air quality issue came to the fore to the occupants of indoor areas with the detection of a large amount of indoor air pollutants such as formaldehyde that causes headache and atopic dermatitis. In order to address this issue, the use of indoor air purifying plants is considered positively as an ecological improvement option. However, the objective performance verification on indoor air-conditioning air volume has not been sufficient. This study aims to verify possible linkage with a building's air conditioning equipment in order to optimize indoor air-conditioning effects by vegetation bio-filters. To this end, 4 different types of air filter material and AHU (Air Handling Unit) system were linked under air conditions of total wind volume of $400,600,800,1,000 \mathrm{CMH}$ and pressure loss by material was monitored objectively. Finally, material-specific power consumption for system operation was calculated to review energy efficiency. As for pressure loss by material, in terms of total wind volume of $800 \pm 1.8 \mathrm{CMH}$, Pre filter was lowest at $-11.69 \mathrm{mmAq}$ and LMF-based vegetation mat was highest at $-219.94 \mathrm{mmAq}$. Based on this, as for material-specific power consumption, the Pre filter, which has the lowest pressure loss, was expected to have power consumption $94.7 \%$ lower than the LMF-based vegetation mat.
\end{abstract}

Keywords: air purifier filter, air volume, HVAC (Heating, Ventilation, and Air Conditioning), power consumption

\section{Introduction}

Recently indoor air pollution test in the daycare center in the Gyeonggi province, Korea revealed that indoor air pollutants such as formaldehyde that causes headache and atopic dermatitis were detected in $25 \%$ of the subject area (Ministry of Environment, 2016). Air quality problems that threaten the health of many unspecified occupants are emerging as major social problems and require more sustainable solutions. In fact, the ecological improvement method using air purifying plants is positively reflecting on the general public, but the objective, quantitative performance verification on indoor air-conditioning air volume has not been sufficient, which presents limitation on securing the market compared with the facility type air purification system. In particular, securing air volume per time is an important factor for indoor air conditioning of unspecified large number of users such as those in multiple use facilities.

This work was carried out with the support of "Cooperative Research Program for Agriculture Science and Technology Development (Project No. PJ012215042017)" Rural Development Administration, Republic of Korea.

Received: September 26, 2017, Revised: October 3, Accepted: October 19, 2017

*Comesponding author: taehankim@smu.ac.kr 
In order to maximize the limited vegetation bio-filter's alternative effect of outdoor fresh air apparatus, it is necessary to link with the existing air handling unit (AHU) and to secure the mechanical performance that can accommodate the optimum filtration rate (NIHHS UARD, 2013).

The previous studies on vegetation bio-filter include the study on indoor air quality purification in a wall-typed botanical bio-filtration system and the improvement of the indoor air quality according to plant growth (Jung, 2015) and the study on determining the wind speed suitable for filter performance and plant growth through monitoring of plant growth, humidity in the air, moisture content of the soil and pressure loss according to flat-typed vegetation bio-filter's wind condition (Choi et al., 2016). The mechanical performance evaluation of AHU is related to the characteristics of the fluid generated in the air filter, and the related studies include the study on identifying test methods and the correlation between dust collection efficiency and differential pressure performance of the air filter considering the influence of microbial pollutants during AHU operation (Ryu, 2001), and the study on time series analysis of the air-conditioning energy consumption according to the pressure difference before and after filtering through long-term simulation (Won et al., 2004).

It is confirmed that a study to directly link the ecological bio-filter with the AHU system in buildings has not been reported to secure sustainable indoor air quality as an analysis of those advanced studies. In terms of air conditioning, the linkage with AHU is required for economical operation of vegetation bio-filter, where total air volume and pressure loss by filter material are important considerations. Therefore, this study is to investigate the pressure loss of vegetation-based material, which plays a role of purifying filter in order to judge the suitability of AHU-linked vegetation bio-filter and to suggest economical plans for review.

\section{Theoretical Consideration}

\section{Vegetation Bio-filter Technology}

The vegetation bio-filter technology, which is an environmentally friendly air purification method using plants, can be divided into special soil-based type and vertical hydroponic type. Two representative commercial products are Fujita's Earth Air Purification System (EAP) and Nedlaw's Living Wall bio-filter in Canada (FACT, 2012). EAP, a special soil-based bio-filter system by "Fujita", a Japanese general construction company, is used to decompose air pollutants generated from roads such as $\mathrm{CO}$ and $\mathrm{NOx}$ through biochemical action of clay minerals and various microorganisms in the soil, which limits filtering speed to $2 \sim 4 \mathrm{~cm} \cdot \mathrm{sec}^{-1}$ to secure response time. On the other hand, the "Living Wall bio-filter" of the Canadian "Nedlaw"s vertical hydroponic type sets the water and rhizosphere mechanisms, not the soil, as the main reaction factor to purify the required air volume of AHU system in the general building. This will ensure a filtration wind speed of $1 \sim 2 \mathrm{~cm} \cdot \mathrm{sec}^{-1}$, which is 50 to 100 times higher than that of a special soil-based type, and provide five occupants within $100 \mathrm{~m}^{2}$ in radius with fresh air through a $1 \mathrm{~m}^{2}$-vegetation bio-filter on average. Those two different types of vegetation bio-filters have different characteristics in terms of removal efficiency and air-conditioning volume, and a complex application plans reflecting both characteristics is required for sound AHU linkage.

\section{Performance Standard of AHU Air Purifying Filter}

In general, the purifying filters applied to the AHU are classified into pre-filter, medium filter, HEPA (high-efficiency particulate air) filter and ULPA (ultra-low particulate air) filter. The vegetation bio-filter in this study has a combination of functions; plant growth base and air purifying filter. However, in order to maximize air conditioning volume that can 
Table 1. Confidence and satisfaction standard of air filter (KITECH: Korea Institute of Industrial Technology).

\begin{tabular}{lcccc}
\hline Type & $\begin{array}{c}\text { Dust Concentration } \\
\left(\mathrm{mg} / \mathrm{m}^{3}\right)\end{array}$ & $\begin{array}{c}\text { Pressure Loss } \\
(\mathrm{mmAq})\end{array}$ & $\begin{array}{c}\text { Capture Efficiency } \\
(\%)\end{array}$ & Use \\
\hline Pre-filter & $0.4 \sim 7$ & $3 \sim 20$ & $70 \sim 90$ (Gravimetric Method) & Pre of Medium Filter \\
Medium I & $0.1 \sim 0.6$ & $8 \sim 25$ & $10 \sim 80(0.3 \mu \mathrm{m} \mathrm{DOP})$ & Pre of HEPA Filter \\
Medium II & $0.3 \geqq$ & $15 \sim 35$ & $80 \leqq(0.3 \mu \mathrm{m} \mathrm{DOP})$ & Final Filter of Clean Room (Class $100,000 \sim)$ \\
HEPA & $0.3 \geqq$ & $8 \sim 50$ & $99.7 \leqq(0.3 \mu \mathrm{m} \mathrm{DOP})$ & Class $100 \sim 10,000$ Final Filter of Clean Room \\
ULPA & $0.3 \geqq$ & $25 \sim 50$ & $99.999 \leqq(0.3 \mu \mathrm{m} \mathrm{DOP})$ & Class $1 \sim 10$ Final Filter of Clean Room \\
\hline
\end{tabular}

replace a fresh air apparatus within the building, it is required to connect with the AHU. KITECH (Korea Institute of Industrial Technology) summarizes the reliability evaluation criteria of the air purifying filter as shown in Table 1 . The performance index consists of applied dust concentration, pressure loss, and capture efficiency, among which the pressure loss is a key index representing the physical performance of the filter reflected in the air conditioning planning and designing. The air filter, in which pressure drop takes place in AHU system, has a direct impact on the energy consumption as the system operates, therefore it is the standard for air conditioning performance (Hashim Kabrein et al., 2016). Generally, in the case of pre-filter made of fiber material, the range of pressure loss is $3 \sim 20 \mathrm{mmAq}$, and it is used as external air processor or pre-filter for a mid-performance filter.

Here, the pressure loss can be interpreted as a performance index, a standard of the physical performance and energy consumption of the air conditioning system, and can be set as a main evaluation index of the bio-filter design performance associated with the AHU.

\section{Differential Pressure and Pressure Loss Measurement Theory}

A suitable test method is required to evaluate the mechanical performance of the air purifying filter and in this study, "AMCA Standard 210" and "KS B 6311: Test Methods for Turbo-Fans and Blowers" were referenced. Here, total airflow, wind speed, and pressure loss can be interpreted as important performance indicators, and total airflow and wind speed can be summarized as follows, which are determined by variables such as expansion coefficient, nozzle differential pressure, density, discharge coefficient, nozzle discharge station area, etc.

$$
\begin{aligned}
& Q\left(\mathrm{~m}^{3} / \mathrm{min}\right)=Y \sqrt{\frac{2 \Delta P}{\rho_{5}}} \sum\left(C A_{6}\right) \\
& Q=\text { Airflow }\left(\mathrm{m}^{3} \cdot \mathrm{sec}^{-1}\right) \\
& Y=\text { Expansion Coefficient } \\
& \triangle P=\text { Nozzle Differential Pressure }(\mathrm{Pa}) \\
& \rho_{5}=\text { Density }\left(\mathrm{kg} / \mathrm{m}^{3}\right) \\
& C=\text { Discharge Coefficient } \\
& A_{6}=\text { Nozzle Discharge Station Area }\left(\mathrm{m}^{3}\right)
\end{aligned}
$$

$V(m / s)=Y C \sqrt{\frac{2 \triangle P}{\rho_{5}}}$

$$
\begin{aligned}
& V=\text { Airflow Velocity }(\mathrm{m} / \mathrm{s}) \\
& Y=\text { Expansion Coefficient } \\
& C=\text { Discharge Coefficient } \\
& \triangle P=\text { Nozzle Differential Pressure }(\mathrm{Pa}) \\
& \rho_{5}=\text { Density }\left(\mathrm{kg} / \mathrm{m}^{3}\right)
\end{aligned}
$$

Generally, in the case of differential pressure type flow measurement, the reduced end area by the nozzles installed for the generation of the differential pressure generates axial flow, which is fluidly changed depending on the fluid density or 
the shape of the mechanism, so that actual measurement is limited. As the effluent coefficient is applied to the nozzle cross section to supplement this limitation, the correction coefficient is expressed as follows by applying the Reynolds number, a major dimensionless number of fluid dynamics, to determine dynamic similitude.

$$
C=0.9986-\frac{7.006}{\sqrt{R e}}+\frac{134.6}{R e}
$$

$$
\begin{aligned}
& C=\text { Discharge Coefficient } \\
& R e=\text { Reynolds Number (Dimensionless) }
\end{aligned}
$$

\section{Study Content and Method}

\section{Study Procedure}

This study systematically summarizes the experimental procedure to evaluate the objective air- conditioning performance of the vegetation bio-filter as follows. First of all, the experiment was designed according to the relevant test standard, and an instrument and monitoring system capable of measuring the differential pressure type flow were constructed. In this study, the driving characteristics of the supply and return fans attached to the AHU system for general building were analyzed and the operating conditions enabling the differentiation of pressure loss by material were configured. Based on this, the reference pressure losses of the AHU and the additional experimental system were measured and the pressure loss by vegetation bio-filter material was monitored. Lastly, the economics of AHU energy consumption based on potential materials was reviewed in connection with the monitoring results.

\section{Design and Development of Experiments}

In order to evaluate the quantitative air-conditioning performance of the vegetation bio-filter, the experimental infrastructure by the differential pressure type flow measurement was built as shown in Fig. 1. The infrastructure consists of a vegetation bio-filter chamber, AHU, and wind tunnel. First, the experimental chamber was designed to facilitate testing per filter material and system type (KSSN, 2014) by referring to "KS I ISO 16000-9: Indoor air — Part 9: Determination of the emission of volatile organic compounds from building products and furnishing - Emission test chamber method". The structure was constructed with a unit volume of 1,000 $\mathrm{mm} \times 1,000 \mathrm{~mm} \times 1,000 \mathrm{~mm}$ based on an aluminum profile of $40 \mathrm{~mm}$ and $\mathrm{PC} t=5 \mathrm{~mm}$.

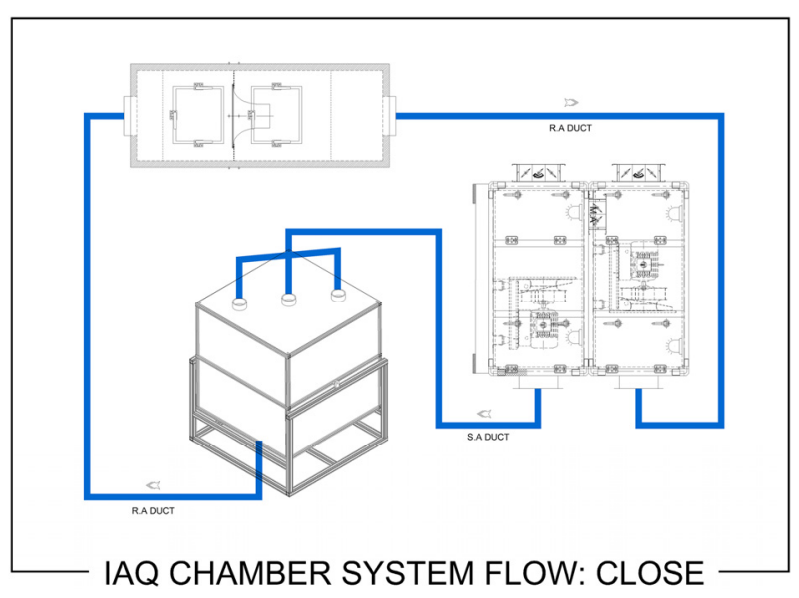

Figure 1. AHU integrated IAQ chamber system.

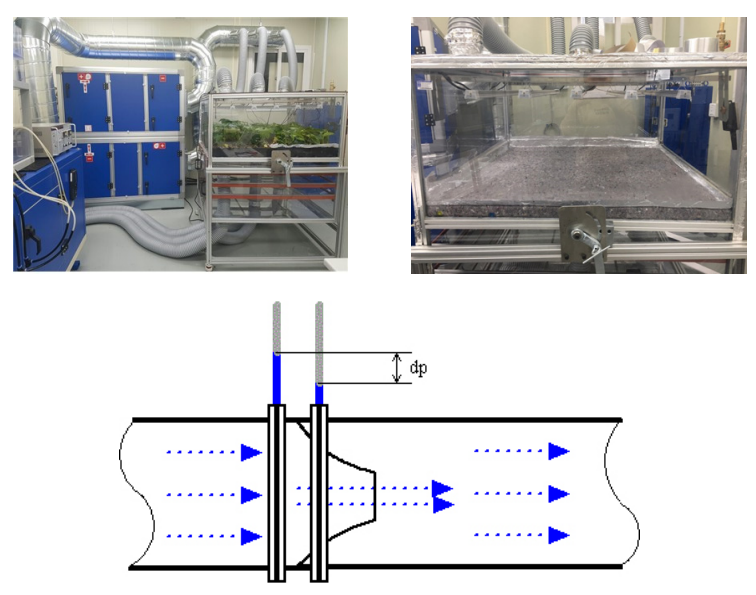

Figure 2. Technical concept of flow nozzles (engineering toolbox). 
The AHU system in the experiment was for general building but excluded cooling and heating facilities, and had the same electric motor of 3,425 rpm in the power section divided into a supply fan and a return fan. In the wind tunnel as shown in Fig. 2, flow nozzles were applied to prevent fluid turbulence and to minimize pressure and friction losses. Here, 3-inch and 7-inch nozzles were selectively used to secure a monitoring band for the rated output of the AHU and in order to ensure data reliability, the nozzle wind speed was maintained at $35 \mathrm{~m} \cdot \mathrm{sec}^{-1}$ or less according to the nozzle diameter to measure differential pressure and pressure loss.

\section{Experimental conditions per vegetation bio-filter material}

Since the vegetation bio-filter should be suitable for both air purification and vegetation growth, the materials that can grow plants were chosen among the materials usable for filter. First, as shown in Table 2, the properties of four different fiber filters - the pre-filters, non-woven fabric, fiber-based vegetation mat, agricultural felt - were summarized.

$10 \mathrm{~mm}$ pre-filter is applied, made up of $100 \%$ PET, a material applied to the pre-filter of general AHU. The non-woven fabric is $20 \mathrm{~mm}$ with structural stability, which improves the tensile strength of general pre-filter. The fabric-based vegetation mat is made of $3 \mathrm{~mm}$ low melting fiber, combination of bottom ash-based artificial soil, and zeolite, solidified by thermosetting at 110 to $210^{\circ} \mathrm{C}$ and $330 \mathrm{~mm} \times 330 \mathrm{~mm} \times 60 \mathrm{~mm}$ in size. The agricultural felt was wasted fiber material with $\mathrm{t}=5 \mathrm{~mm}$. In addition, as shown in Table 3, long-term exposure monitoring confirms the growth suitability of the selected bio-filter material. Here, the fabric-based vegetation mat is confirmed to have stable growth even in outdoor

Table 2. Material specification of vegetation based bio-filter.

\begin{tabular}{llll}
\hline Bio-Filter Material Type & Pre Filter & Non-Woven Fabric & Fiber-based Vegetation Mat \\
\hline
\end{tabular}

Table 3. Evaluation of vegetation growth.

$\begin{gathered}\text { Non-Woven } \\ \text { Fabric }\end{gathered}$
$\begin{gathered}\text { Fiber-based } \\ \text { Vegetation Mat }\end{gathered}$ Agricultural Felt

Table 4. Specification of monitoring system.

\begin{tabular}{lcc}
\hline & $\begin{array}{c}\text { Climate Measuring } \\
\text { Instrument }\end{array}$ & $\begin{array}{c}\text { Temperature-Humidity } \\
\text { Sensor }\end{array}$ \\
Image & TESTO, 480 & TESTO, $175 \mathrm{H} 1$ \\
\hline Model & $-100 \sim+100 \mathrm{hPa}$ & $-20 \sim+55^{\circ} \mathrm{C} / 0 \sim 100 \%$ RH \\
\hline Range &
\end{tabular}


exposure of 20 months or more. The felt for agriculture was exposed for two months, the pre filter was two months, and the non-woven fabric is exposed for one month or more. The objective growth stability results for the long-term exposure test will be presented in subsequent studies.

\section{Monitoring Design}

In this study, the pressure loss of the reference material and the subject materials was measured, and the differential pressure gauge and the temperature and humidity sensor of Table 4 were installed in the experimental area to monitor the air flow environment. First, the fan condition sensitive to the differential pressure change according to the driving characteristics of the supply and return fans attached to AHU was created and the experimental environment of 400, 600, 800 , and 1,000 $\mathrm{CMH}$ in the total air volume was established accordingly. Pressure loss measurements by material were conducted in accordance with "AMCA Standard 210" and "KS B 6311: Test Methods for Turbo-Fans and Blowers" (AMCA, 2016; KSSN, 2014).

\section{Calculating AHU energy consumption linked with pressure loss}

The pressure loss by material of vegetation bio-filter affects the energy consumption of the indoor air conditioning system linked with AHU. To evaluate this, Life Cycle Costing evaluation study (Arnold et al., 2005) of the air filter, published by the American Society of Heating, Refrigerating and Air-Conditioning Engineers (ASHRAE) was referred to. The study shows the energy consumption of the air conditioning system, covering the total air flow, average pressure loss, time in operation, fan efficiency, as in the following formula.

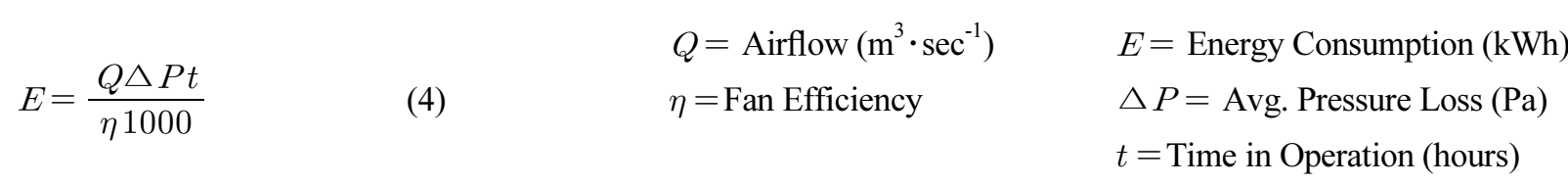

In this study, the possible energy consumption of the bio-filter per material was measured under the condition of 400, 600,800 and 1,000 CMH in total air flow if it is linked with AHU. As the fan efficiency was set to 58\% with driving condition for one week based on the operation of 10 hours a day, the economic efficiency by material was predicted.

\section{Conclusion and Consideration}

\section{AHU operation environment configuration for pressure loss measurement}

In order to obtain accurate results of pressure loss by material, the condition was the same as the condition of fan driving condition in general AHU system. Experimental conditions were divided into independent and simultaneous operation of supply and return fans. The pressure loss was measured under the variations of non-filter, two pre-filters and four pre-filters with the basic condition of a flow nozzle of 7 inches and a total air flow rate of $800 \pm 0.9 \mathrm{CMH}$. The pressure loss by material is shown in Fig. 3, which shows time series analysis and box plot. In the case of single driving of return fan, the average of $-41.5 \mathrm{mmAq},-42.4 \mathrm{mmAq}$, and $-43.0 \mathrm{mmAq}$ were found in the non-filter, two pre-filters and four pre-filters respectively, confirming that higher pressure loss per material is discerned in comparison with other conditions. 

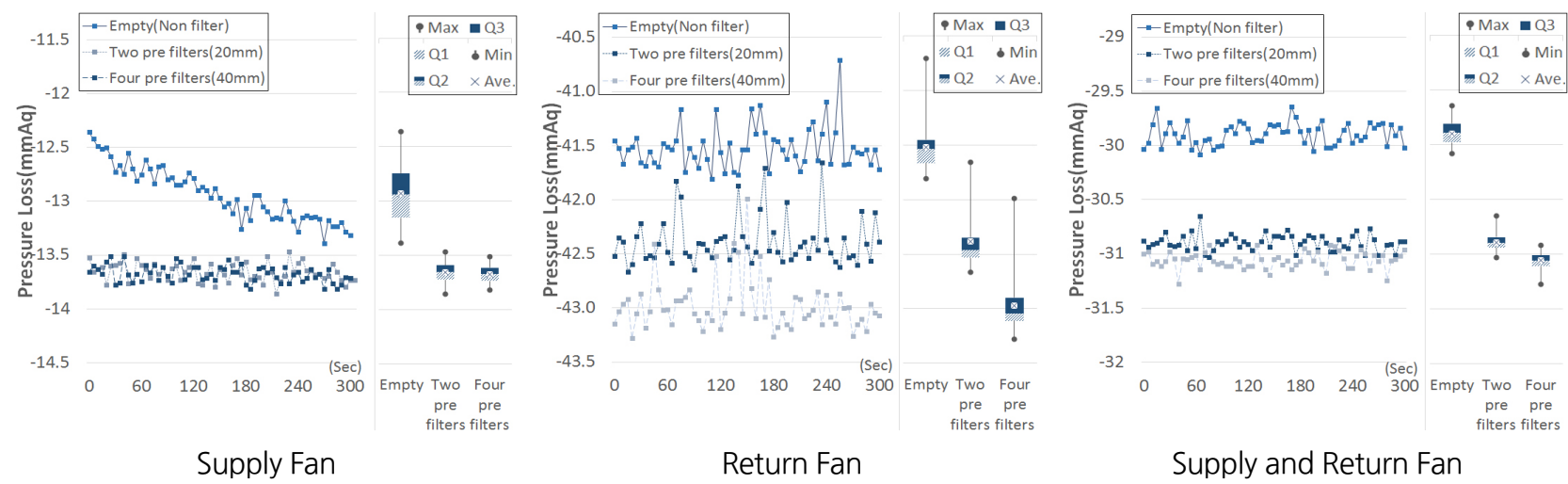

Figure 3. Stability operation of $\mathrm{AHU}$ within pre-filter scenarios (unit: $\mathrm{mmAq}$ ) (pre-filter: Weight: $65 \pm 6 \mathrm{~g} / \mathrm{m}^{3}$, Tensile Strength: MD $78.4 \pm 29.4 \mathrm{~N} / \mathrm{cm}^{2}$ ).

\section{Reference Pressure Loss according to Static Pressure in the Experiment}

The reference pressure loss was measured to calculate material-specific pressure loss against pressure loss of non-filter condition. The experiment area is made up of experimental chamber, AHU, and wind tunnel. Pressure loss due to static pressure was measured according to total air flow conditions. The total airflow was $400 \pm 1.5,600 \pm 2.6,800 \pm 11.7$, and 1,000 $\pm 17.9 \mathrm{CMH}$, respectively and pressure loss of non-filter condition was analyzed as shown in Fig. 4 and Table 5.

The highest standard deviation was recorded at a total air flow of 1,000 $\pm 17.9 \mathrm{CMH}$, and a relatively stable pressure loss was recorded at a total air flow of $600 \pm 2.6 \mathrm{CMH}$ or less. As shown in the above analysis, the pressure loss can be summarized on non-filter basis, and the average pressure loss per total air volume was reflected in the calculation of the pressure loss by material.

\section{Material-Specific Pressure Loss Evaluation}

The total pressure loss of the pre-filter, the non-woven fabric, the fabric-based vegetation mat, and the agricultural felt selected as vegetation bio-filter materials are shown in Fig. 5. Here, the average total air volume per material was set to $400 \pm 0.6,600 \pm 1.2,800 \pm 3.3$, and 1,000 $\pm 11.3 \mathrm{CMH}$. The pre-filters recorded a low pressure loss of -3.0 - 37.3 Pa, so it was selected as the reference material. Here, the reversal phenomenon is confirmed on the basis of the total air volume 800 $\mathrm{CMH}$, which is a compensation phenomenon due to low nozzle air velocity and pressure loss after replacing three inch flow nozzle, which recorded more than $35 \mathrm{~m} \cdot \mathrm{sec}^{-1}$ of nozzle wind speed, with seven inch nozzle. On the other hand, other vegetation bio-filter materials recorded significant pressure loss differences compared to the reference material. First, the pressure loss of the non-woven fabric against the pre-filter was about $21 \sim 57 \%$. The other pressure loss levels were $5 \sim 23 \%$ of the fabric-based vegetation mat and $9 \sim 39 \%$ of the agricultural felt.

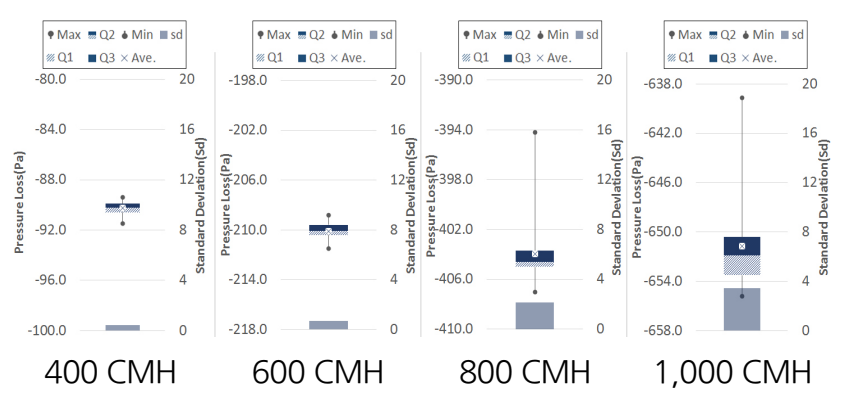

Figure 4. Pressure loss of non-filter condition (unit: $\mathrm{Pa}$ ).
Table 5. Pressure loss of non-filter condition (unit: $\mathrm{Pa}$ ).

\begin{tabular}{|c|c|c|c|c|c|}
\hline \multicolumn{2}{|c|}{ Air Flow } & $400 \mathrm{CMH}$ & $600 \mathrm{CMH}$ & $800 \mathrm{CMH}$ & $1,000 \mathrm{CMH}$ \\
\hline \multirow{4}{*}{$\begin{array}{l}\text { Pressure } \\
\text { Loss }\end{array}$} & $\min$ & -91.5 & -211.5 & -407.0 & -655.2 \\
\hline & avg & -90.3 & -210.1 & -404.0 & -651.2 \\
\hline & $\max$ & -89.4 & -208.8 & -394.2 & -639.1 \\
\hline & $\mathrm{sd}$ & 0.4 & 0.7 & 2.2 & 3.5 \\
\hline
\end{tabular}




\section{Energy Consumption of AHU by Material and Assessment}

The energy consumption of material-specific bio-filter when linking with AHU is calculated as the following Table 6, based on the total wind volume of the pre-filter as the reference material. Here, the average total air volume was set in accordance with the pressure loss evaluation for each material. Similar to the pressure loss ratio relative to the reference material, the energy consumption of fiber-based vegetation mat, agricultural felt, and non-woven fabric were recorded. First, in the case of non-woven fabric, an additional energy consumption of 1,475.5 Wh is required in comparison with the reference material under the condition of 1,000 CMH. For agricultural felts, an additional energy consumption of 3,488.4 Wh compared to the reference material was recorded under the same air volume. Lastly filter-based vegetation mat showed the maximum additional energy consumption of 7,754.1 Wh compared to the reference material under the same air volume condition.

The energy consumption of vegetation bio-filters by material were different according to the total air volume as indicated in Fig. 6. First, the energy consumption tendency most similar to the reference material was shown in the condition of $600 \mathrm{CMH}$, and the additional energy consumption of $174 \sim 438 \%$ was calculated by material. On the other hand, the maximum energy consumption compared to the reference material showed differences by material. The non-woven fabric was $800 \mathrm{CMH}$, the agricultural felt and filter-based vegetation mat showed the highest energy consumption difference under the condition of $400 \mathrm{CMH}$. Under the maximum air volume condition, which is 1,000 $\mathrm{CMH}$, the energy consumption compared to the reference material tended to decrease by material.

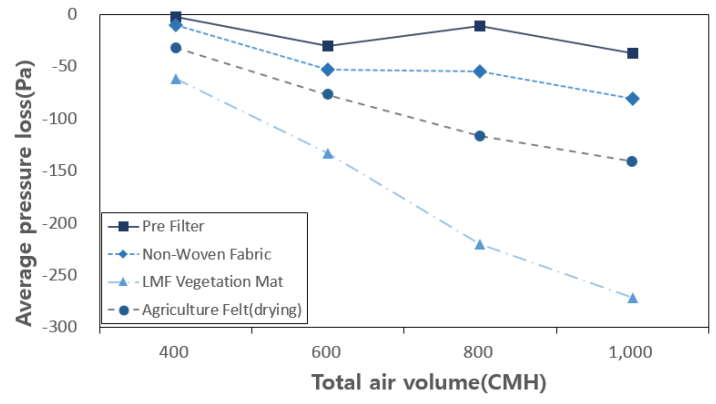

Figure 5. Pressure loss by bio-filter material within air flow scenarios

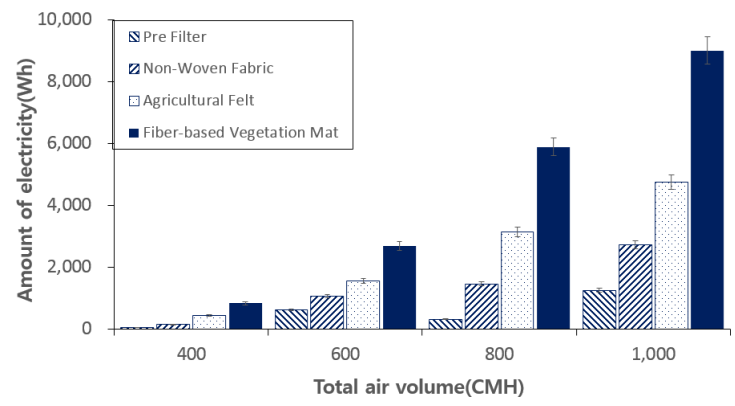

Figure 6. Energy consumption of AHU by bio-filter material within air flow scenarios

Table 6. Energy consumption of AHU by bio-filter material within air flow scenarios

\begin{tabular}{|c|c|c|c|c|c|c|c|}
\hline $\begin{array}{l}\text { Material } \\
\text { Type }\end{array}$ & $\begin{array}{l}\text { Air Volume } \\
\quad(\mathrm{CMH})\end{array}$ & $\begin{array}{l}\text { Pressure Loss } \\
(\mathrm{Pa})\end{array}$ & $\begin{array}{c}\text { Power Consumption } \\
\text { (Wh) }\end{array}$ & $\begin{array}{l}\text { Material } \\
\text { Type }\end{array}$ & $\begin{array}{l}\text { Air Volume } \\
\quad(\mathrm{CMH})\end{array}$ & $\begin{array}{l}\text { Pressure Loss } \\
\qquad(\mathrm{Pa})\end{array}$ & $\begin{array}{l}\text { Power Consumption } \\
\text { (Wh) }\end{array}$ \\
\hline \multirow{4}{*}{ Pre Filter } & 400.4 & -3.0 & 39.9 & \multirow{4}{*}{$\begin{array}{c}\text { Fiber-based } \\
\text { Vegetation } \\
\text { Mat }\end{array}$} & 399.6 & -61.6 & 825.1 \\
\hline & 600.4 & -30.4 & 612.1 & & 599.1 & -133.5 & $2,683.2$ \\
\hline & 799.8 & -11.7 & 313.5 & & 801.0 & -219.9 & $5,888.1$ \\
\hline & $1,002.6$ & -37.3 & $1,252.0$ & & $1,001.5$ & -271.7 & $9,006.1$ \\
\hline \multirow{4}{*}{$\begin{array}{l}\text { Non-Woven } \\
\text { Fabric }\end{array}$} & 400.6 & -10.4 & 139.8 & \multirow{4}{*}{$\begin{array}{l}\text { Agricultural } \\
\text { Felt }\end{array}$} & 399.9 & -32.6 & 436.9 \\
\hline & 598.8 & -53.2 & $1,067.2$ & & 599.7 & -77.3 & $1,553.2$ \\
\hline & 796.7 & -54.6 & $1,459.4$ & & 798.6 & -219.94 & $3,138.3$ \\
\hline & $1,001.7$ & -81.2 & $2,727.5$ & & 988.7 & -271.72 & $4,740.4$ \\
\hline
\end{tabular}




\section{Conclusions}

The purpose of this study is to identify the pressure loss per material, determining the mechanical suitability in case of linking with AHU in order to improve the efficiency of vegetation bio-filters. The results of the study can be summarized as follows. First, in order to meet the purpose of forming a laboratory chamber for discerning the pressure loss per vegetation bio-filter material, experimental conditions were set up by using independent driving of the return fan to reflect the driving characteristics of the AHU. As a result of measuring the static pressure of the experimental chamber in order to draw the result of material specific pressure loss, a stable standard deviation of $0.4 \sim 0.7$ was recorded in the total air volume of $400 \sim 600 \mathrm{CMH}$. As a result of measuring the pressure loss per material, the non-woven fabric recorded performance close to $60 \%$ higher than the pre-filter in comparison with other vegetation bio-filters, which can lead to the judgement that the non-woven fabric is a proper material in air conditioning. As a result of estimating the energy consumption by material, it is interpreted that in the case of the vegetation bio-filter with the unit test standard of $1 \mathrm{~m}^{2}$, maintaining the total wind volume to $600 \mathrm{CMH}$ is economically more efficient air conditioning conditions over the general pre-filter.

Based on the above results, it was possible to obtain basic data on the air conditioning characteristics that can improve the air conditioning efficiency by linking the AHU system of the general building to the limit of the study on the conventional vegetation bio-filter, which was limited in the amount of air conditioning per unit area. This is expected to contribute to the academic and industrial understanding of vegetation bio-filters by providing objective performance indicators of filter materials that can be planted in the air condition system of a building. However, the verification of the environment in the experimental chamber and the tests which excluded the planting and irrigation are considered to be limitations of this study. These considerations should be reflected in the follow-up study to supplement the experiment results.

\section{References}

AMCA international. 2016. AMCA Standard 210: Laboratory Methods of Testing Fans for Certified Aerodynamic Performance Rating. Retrieved from https://aw.resource.org/pub/us/cfr/ibr/001/amca.210.1999.pdf

Arnold, B.D., D.M. Matela, and A.C. Veeck. 2005. Life-cycle costing of air filtration. J. Am. Soc. Heat. Refrig. Air-cond. Eng. 47(12):30-32.

CHoi, B., M.Y Chun, and C.h. Lee. 2014. Evaluation for Soil Moisture Stabilization and Plant Growth Response in Horizontal Biofiltration System Depending on Wind Speed and Initial Soil Moisture. J. Korean Plant Res. 27(5): 546-555.

Choi, J.Y., S.A. Park, S.J. Jung, J.Y. Lee, and K.C. Son. 2016, May. Measuring of psychophysiological response of human according to the index of greenness of interior space. Paper presented at the $104^{\text {th }}$ Spring Conference on Korean Soc. Hortic. Sci., Changwon, Korea.

FACT (Foundation of Agri. Tech. Commercialization \& Transfer). 2012. Urban agricultural industry trend Report. Retrieved from http:/www.google.co.kr/url?sa=t\&rct=j\&q=\&esrc=s\&frm=1\&source=web\&cd=1\&cad=rja\&uact=8\&ved=0ahUKE wil06P2pLDXAhUNO7wKHUnWD6cQFggkMAA\&url=http\%3A\%2F\%2Fwww.nihhs.go.kr\%2Fn_common\%2FnDo wnload.

Hashim Kabrein, M.Z., M.Z.M Yusof, and A.M. Leman. 2016. Progresses of filtration for removing particles and gases pollutaants of indoor. ARPN J. Eng. Appl. Sci. 11(6):3633-3639.

Jung, S.K., M.Y. Chun, and C.H. Lee. 2015. Plant growth responses and indoor air quality purification in a wall-typed botanical biofiltration system. J. Korean Plant Res. 28(5):665-674. 
KSSN (Korean Standard Service Network). 2014. KS I ISO16000-9. Retrieved from https://standard.go.kr/KSCI/standardIntro/ getStandardSearchView.do?menuId=919\&topMenuId=502\&upperMenuId=503\&ksNo=KSIISO16000-9\&tmprKsNo= KSIISO16000-9\&reform $\mathrm{No}=02$

Ministry of Environment. 2016. Result of risk assessment of air cleaner, air conditioner OIT antibacterial filter. Retrieved from http://www.me.go.kr/home/web/board/read.do?boardMasterId=1\&boardId=664290\&menuId=286

NIHHS UARD (National Institute of Horticultural and Herbal Science Urban Agriculture Research Division), 2013. The birth of 'Bio Monday' to purify air and save energy. Retrieved from http://www.rda.go.kr/board/board.do?mode= view\&prgId $=$ spe_briefing\&dataNo $=100000515318$

Nedlaw. 2008. Understanding the Difference between a green wall and a bio-filter. Retrieved from http://nedlawlivingwalls. com/wp-content/uploads/Understanding-the-Difference-bw-a-Green-Wall-and-a-Biofilter.pdf

Ryu, J.S., Y.H. Jung, and J.Y. Sohn. 2001. Air filter performances in building air conditioners. Proceeding of the Architectural Institute Korea, Korea, 21(2):881-884

Won, K.H., R.Y. Kwak, and J.H. Huh. 2004. Evaluation of energy consumption of HVAC system for air filter pressure difference change in commercial buildings. Korean J. Air-Cond. Refrig. Eng. 16(12):1227-1234. 